University of Nebraska - Lincoln

DigitalCommons@University of Nebraska - Lincoln

Faculty Publications: Department of

Entomology

Entomology, Department of

2006

\title{
Absence of Genetic Divergence Between Western Corn Rootworms (Coleoptera: Chrysomelidae) Resistant and Susceptible to Control by Crop Rotation
}

Nicholas Miller

University of Nebraska-Lincoln, nmiller11@iit.edu

K. S. Kim

USDA-ARS, CICGRU, Genetics Laboratory, lowa State University

S. T. Ratcliffe

University of Illinois at Urbana-Champaign

A. Estoup

UMR INRA-IRD-CIRAD-Agro. M, Campus International de Baillarguet

T. Guillemaud

Centre INRA-UNSA de Sophia Antipolis

Follow this and additional works at: https://digitalcommons.unl.edu/entomologyfacpub

Part of the Entomology Commons

Miller, Nicholas; Kim, K. S.; Ratcliffe, S. T.; Estoup, A.; and Guillemaud, T., "Absence of Genetic Divergence Between Western Corn Rootworms (Coleoptera: Chrysomelidae) Resistant and Susceptible to Control by Crop Rotation" (2006). Faculty Publications: Department of Entomology. 248.

https://digitalcommons.unl.edu/entomologyfacpub/248

This Article is brought to you for free and open access by the Entomology, Department of at DigitalCommons@University of Nebraska - Lincoln. It has been accepted for inclusion in Faculty Publications: Department of Entomology by an authorized administrator of DigitalCommons@University of Nebraska - Lincoln. 


\title{
Absence of Genetic Divergence Between Western Corn Rootworms (Coleoptera: Chrysomelidae) Resistant and Susceptible to Control by Crop Rotation
}

\author{
N. J. MILLER, ${ }^{1}$ K. S. KIM ${ }^{2}$ S. T. RATCLIFFE, ${ }^{3}$ A. ESTOUP,${ }^{4}$ D. BOURGUET,${ }^{4}$ AND T. GUILLEMAUD ${ }^{1}$
}

\section{J. Econ. Entomol. 99(3): 685-690 (2006)}

\begin{abstract}
The western corn rootworm, Diabrotica virgifera virgifera LeConte (Coleoptera: Chrysomelidae), is a major pest of corn, Zea mays L., in North America that has recently invaded Europe. A loss of ovipositional fidelity to cornfields has allowed the species to circumvent crop rotation as a means of control in part of its range in the United States. Analyses of variation at eight microsatellite loci provided no evidence for general genetic differentiation between samples of western corn rootworm collected in soybean, Glycine max (L.) Merr., fields and those collected in cornfields both inside and outside the rotation-resistance problem area. This result suggests that few or no barriers to gene flow exist between rotation-resistant and -susceptible rootworm populations. The implications of this result for the management of western corn rootworm in North America and Europe are discussed.
\end{abstract}

KEY WORDS western corn rootworm, crop rotation, adaptation, population genetics, microsatellite.

The ability of pest populations to adapt to anthropogenic selection pressures provides many of the classic examples of evolutionary processes (Devonshire et al. 1998, Raymond et al. 1998, Ferré and Van Rie 2002) and represents a significant threat to human health and sustainable food supplies. The western corn rootworm, Diabrotica virgifera virgifera LeConte (Coleoptera: Chrysomelidae) is of particular importance in this respect because it has a history of adapting to a range of pest control techniques.

The western corn rootworm is an important pest of cultivated corn, Zea mays L. Damage to corn is mainly caused by the larvae feeding on the root system, disrupting water and nutrient uptake as well as leaving the plants prone to lodging, making them difficult to harvest (Kahler et al. 1985, Levine et al. 2002). The species range began to expand rapidly from the western part of the Corn Belt in the 1950s, reaching the east coast during the 1980s (Metcalf 1983, Spencer et al. 2005). More recently, the pest has invaded Europe. First observed near Belgrade, Serbia, in 1992, it has become widespread in central Europe and continues to spread into western and eastern Europe (Kiss et al.

\footnotetext{
${ }^{1}$ Biologie des Populations en Interaction, UMR INRA-UNSA 1112 ROSE, Centre INRA-UNSA de Sophia Antipolis, 400 Route des Chappes, 06930 Sophia Antipolis, France.

2 2) USDA-ARS, CICGRU, Genetics Laboratory, Iowa State University, Ames, IA 50011.

${ }^{3}$ Department of Crop Sciences, University of Illinois, S-316 Turner Hall, 1102 S. Godwin Ave., Urbana, IL 61801.

${ }^{4}$ Centre de Biologie et de Gestion des Populations, UMR INRAIRD-CIRAD-Agro. M, Campus International de Baillarguet, CS 30 016, 34988 Montferrier/Lez cedex, France.
}

2005 ) by both intracontinental redistribution and repeated transatlantic introductions (Miller et al. 2005).

A key factor in the emergence of the western corn rootworm as a major pest of corn has been its ability to confound control measures. For example, populations have evolved resistance to several insecticides (Ball and Weekman 1962, Meinke et al. 1998). An alternative to chemical insecticides is regular rotation between corn and nonhost plant crops, typically soybean, Glycine $\max (\mathrm{L}$.) Merr., in the United States. This technique exploits the fidelity of ovipositing females to cornfields, the univoltine life cycle in which the eggs spend the winter in diapause in the soil, and the inability of the larva to survive on soybean roots. Eggs laid in rotated cornfields hatch into soybean crops and thus the larvae die because they cannot find suitable food. Damage to rotated corn was first observed in 1987 in east central Illinois (Levine and Oloumi-Sadeghi 1996). The area in which crop rotation is compromised has subsequently expanded to cover much of Illinois as well as parts of several neighboring states (O'Neal et al. 2002). The circumvention of crop rotation ("rotation resistance") is associated with increased densities of adult western corn rootworms, especially females, in soybean fields (Spencer et al. 1997, 1998, 1999b). Crucially, there is also an increase in oviposition outside cornfields, including into soybean fields (Spencer et al. 1997, Rondon and Gray 2004). Eggs laid in soybean crops will generally find themselves in fields rotated to corn the following year and thus the larvae can find appropriate food and survive. Unfortunately, the problem is less well understood at the level of the individual behavioral phe- 
notype. Laboratory studies comparing individuals from "resistant" and "susceptible" populations have not revealed significant differences in their attraction to soybeans or their tendency to feed on them (Spencer et al. 1999a, O’Neal et al. 2002), in oviposition behavior (Mabry et al. 2004), or in their tendency to leave older corn plants (O’Neal et al. 2004).

Computer simulation studies have shown that selection of an adaptive allele at a single locus could lead to the evolution of rotation resistance in a region where up to $98 \%$ of corn is rotated (Onstad et al. 2001). However, the lack of a clearly defined phenotype means that, to date, a genetic basis for rotation resistance has not been conclusively demonstrated. Consequently, the hypothesis that rotation resistance is due to corn phenology also has been proposed (O’Neal et al. 2002, 2004), although field experiments have shown that manipulating corn phenology does not cause rotation-susceptible populations to oviposit in soybean fields (Pierce 2003). Furthermore, the well documented geographic spread of rotation resistance from its point source in Ford County, Illinois (Levine and Oloumi-Sadeghi 1996, Onstad et al. 1999, Levine et al. 2002), argues strongly that the trait is genetically based. For the phenological hypothesis to be true requires that systematic changes in corn phenology spread, and continue to spread, from the point source in Ford County and that no such instances of corn phenology promoting emigration into soybean presently occurs, or has occurred in the past, anywhere outside the zone of spread. Notwithstanding the proposal by O'Neal et al. (2004) that the behavioral plasticity model is a simpler explanation than a genetic mechanism, a mutation anywhere in a gene controlling fidelity to corn that disables that gene is a simple mechanism that would lead to rotation resistance. Therefore, it seems apparent that a genetic mechanism causing rotation resistance is the most parsimonious explanation given the current evidence.

Both the adaptation and phenological hypotheses share the common prediction that the phenomenon of rotation resistance will not produce a general barrier to gene flow. Given that gene flow seems to be sufficiently high to maintain homogenous allele frequencies throughout most of the Corn Belt, at least over the period encompassing the eastward range expansion beginning in the 1950s (Kim and Sappington 2005a), an absence of population genetic structuring is expected both within the region where rotation resistance is a problem and between this region and the surrounding area. However, circumstances can be envisaged under which this prediction might not hold. Although an absence of genetic structuring seems likely, O’Neal et al. (2004) list several different terms that have been applied to the phenomenon, including "strain," which implies a level of genetic isolation. A degree of nonrandom mating could occur due to a bias toward matings between individuals emerging in the same field. Such a bias toward within-field matings is plausible because 1) female western corn rootworms normally mate before leaving their natal field (Quiring and Timmins 1990), 2) adult males emerge only a few days before the females (Quiring and Timmins 1990), 3) trivial movement by both sexes does not normally exceed $10 \mathrm{~m}$ per day (Spencer et al. 2003), and 4) females are thought generally to mate only once (Hill 1975, Branson et al. 1977). Because individuals emerging in first year corn are the offspring of females that oviposited in soybean (i.e., offspring of rotation-resistant females), a bias toward mating within the natal field might translate into preferential mating between rotation-resistant rootworms. Forces likely to counteract this bias include interfield dispersal by males and oviposition by rotation-resistant females in continuous corn where their offspring can mate with those of rotation-susceptible individuals. The latter situation would occur if the hypothesized mechanism of Spencer et al. (1999a) of a loss of fidelity to corn is responsible for rotation resistance, rather than a positive attraction to soybean. Pleiotropic effects of an adaptation to crop rotation also might promote nonrandom mating. Pleiotropic effects on developmental time that could skew mating probabilities have been observed in association with resistance to Bacillus thuringiensis $(\mathrm{Bt})$ toxins in both the pink bollworm, Pectinophora gossypiella (Saunders) (Liu et al. 1999), and diamondback moth, Plutella xylostella (L.) (Cerda and Wright 2002).

Where crop rotation is no longer effective in controlling rootworms, an attractive alternative is the use of transgenic corn producing insecticidal proteins derived from $B$. thuringiensis (Onstad et al. 2003). The long-term sustainability of Bt transgenic cultivars relies on the implementation of a refuge strategy (USEPA 2003), which assumes random mating between susceptible individuals from the nontransgenic refuge and any Bt-resistant individuals emerging from nearby transgenic crops. Any local population structuring could violate this assumption and should be taken into account when formulating and evaluating the refuge strategy. Thus, it is important to confirm the predicted absence of local population structuring associated with resistance to crop rotation. It is presently unclear whether any bias toward nonrandom mating exists in association with rotation resistance or whether any counteracting forces are sufficient to maintain panmixia. Testing this prediction also will determine whether rotation-resistant western corn rootworms should be considered as a distinct strain, genetically isolated from the wider population. In the current study, we therefore undertook a fine-scale population genetics analysis of the western corn rootworm in the context of resistance to crop rotation to test the null hypothesis of no genetic structuring.

\section{Materials and Methods}

Sample Collection. Samples were collected from seven sites in east central Illinois (Fig. 1) in 2003 (i.e., within the rotation-resistance problem area). Two samples of $\approx 30$ adult western corn rootworms were collected at each site, one from a cornfield and one from a nearby soybean field. Samples from soybean were expected to contain mostly rotation-resistant 


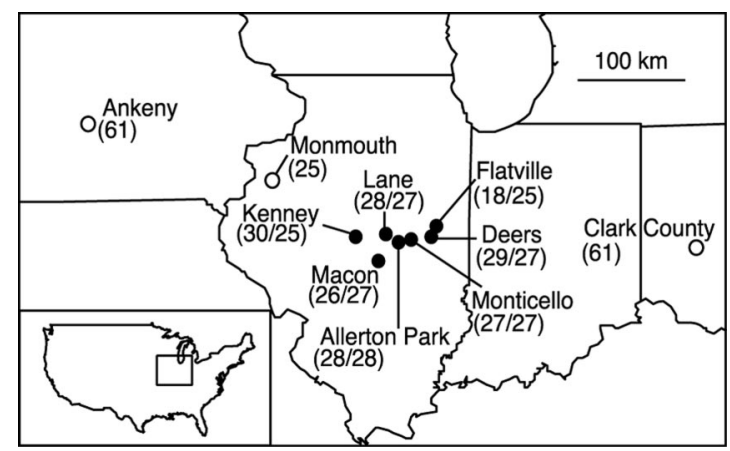

Fig. 1. Locations of western corn rootworm sampling sites in the United States. Figures in parentheses indicate the number of individuals genotyped from corn or corn-soybean. Filled circles indicate sites within the area affected by rotation resistance. Open circles indicate those outside the rotation-resistance area.

individuals, whereas those from corn were expected to contain rotation-resistant, and, potentially, -susceptible individuals in unknown proportions. Because it is uncertain whether rotation-resistant beetles have entirely replaced their -susceptible counterparts in the problem area, a sample of 25 individuals from outside the problem area (representing rotation-susceptible individuals) was collected from a cornfield at Monmouth in northwestern Illinois (Fig. 1) in 2002. This latter sample was supplemented with genotypic data collected from two samples of 61 individuals from cornfields outside the problem area from Ankeny, IA, and Clark County, Ohio (Kim and Sappington 2005a).

Microsatellite Analysis. Template material for polymerase chain reaction (PCR) amplification of microsatellites was prepared from a single leg per individual in a $25-\mu \mathrm{l} 5 \%$ Chelex (Bio-Rad, Hercules, CA), $2 \mu \mathrm{g} / \mu \mathrm{l}$ proteinase K (Euromedex, Mundolsheim, France) solution following Estoup et al. (1996). Dinucleotide (denoted DVV-D*) and trinucleotide (DVV-T*) microsatellites identified by Kim and Sappington (2005b) were amplified in two separate multiplex PCR reactions. The first reaction amplified DVV-D1, DVV-D2, DVV-D4, DVV-D9, DVV-D10, DVV-D11, and DVV-T2 by using a primer annealing temperature of $57^{\circ} \mathrm{C}$. The second reaction amplified DVV-D3, DVV-D5, DVV-D6, DVV-D7, DVV-D8, DVV-D12, and DVV-T1 plus DVVET1, an unpublished microsatellite identified from an Expressed Sequence Tag database (K.S.K., unpublished; forward primer, ATGAAATGCCCGATGAAAAG and reverse primer, TTCCAACATAGTTGTCATCATCC) by using an annealing temperature of $56^{\circ} \mathrm{C}$. Both multiplex reactions were carried out using QIAGEN multiplex PCR kits (QIAGEN GmbH, Hilden, Germany) according to the manufacturer's instructions. The forward primer for each microsatellite was labeled with a fluorescent dye, allowing $P C R$ products to be detected on an ABI 3100 DNA sequencer (Applied Biosystems, Foster City, CA). Allele scoring between this study and the Iowa and Ohio data of Kim and Sappington (2005a) was standardized using a panel of common reference DNA samples.
Data Analysis. Loci DVV-D1, DVV-D3, DVV-D6, DVV-D7, DVV-D10, DVV-D12, and DVV-T1 were excluded from the analyses because they have been shown to bear nonamplifying null alleles (Kim and Sappington 2005b) that could produce misleading results. The number of alleles per locus and observed and expected heterozygosities were calculated using GENEPOP 3.4 (Raymond and Rousset 1995).

Several approaches were taken to investigate the degree of population genetic structuring. A hierarchical F-statistics analysis in which samples were nested within crops (corn or soybean) within zones (inside the rotation resistance problem area or outside) was conducted using HIERFSTAT (Goudet 2005). Randomization procedures implemented in HIERFSTAT were used to test the significance of population structuring at each hierarchical level. Where significant departures of $F$-statistics from zero were observed, the hypothesis of allele frequency homogeneity was examined in detail by performing Fisher exact tests for each pair of samples using GENEPOP. Potentially, differentiation between samples from corn and soybean within the rotation resistance problem area could be masked by a high frequency of resistant individuals in corn. Such mixing would, however, produce a Wahlund effect, i.e., an excess of homozygous genotypes compared with their expected frequencies under Hardy-Weinberg equilibrium (Hartl and Clark 1997). Consequently, exact tests for HardyWeinberg and linkage equilibria were conducted for the problem area samples by using GENEPOP. Sequential Bonferroni corrections were applied to the $P$ values for each locus or locus-pair to account for the replicate tests over samples. Finally, the number of distinct populations $(K)$ present in the set of samples was estimated with the aid of STRUCTURE (Pritchard et al. 2000). STRUCTURE was used to estimate $\operatorname{Pr}(X \mid K)$, the probability of the observed set of genotypes $(X)$, conditional on the number of genetically distinct populations, $K$ for values of $K$ between 1 and 4 . The program was run for $10^{6}$ iterations preceded by an initial burn-in of $10^{5}$ iterations, an admixture model of individual ancestry and correlated allele frequencies among populations. Five runs were performed for each value of $K$ to verify that estimates of $\operatorname{Pr}(X \mid K)$ were consistent between runs. The posterior probabilities, $\operatorname{Pr}(K \mid X)$, were then calculated according to Pritchard et al. (2000).

\section{Results}

All eight microsatellites were polymorphic in the Illinois samples collected for this study. The mean number of alleles per locus and per sample ranged from 2.82 to 13.88 , and average expected heterozygosities ranged from 0.24 to 0.87 (Table 1). Within the rotation-resistance problem area, only one case of Hardy-Weinberg disequilibrium (locus DVV-D5 in the Flatville corn sample) and two cases of linkage disequilibrium (DVV-D4 versus DVV-D9 in the Lane corn sample and DVV-D11 versus DVV-T2 in the Monticello corn sample) were significant after Bon- 
Table 1. Measures of microsatellite diversity in samples of western corn rootworm from Illinois

\begin{tabular}{lccr}
\hline \hline \multicolumn{1}{c}{ Locus } & $\begin{array}{c}\text { Mean no. } \\
\text { alleles (SE) }\end{array}$ & $\begin{array}{c}\text { Mean observed } \\
\text { heterozygosity (SE) }\end{array}$ & $\begin{array}{c}\text { Mean expected } \\
\text { heterozygosity (SE) }\end{array}$ \\
\hline DVV-D2 & $7.76(0.3)$ & $0.76(0.02)$ & $0.75(0.01)$ \\
DVV-D4 & $6.82(0.19)$ & $0.71(0.02)$ & $0.7(0.01)$ \\
DVV-D5 & $2.82(0.16)$ & $0.22(0.02)$ & $0.24(0.02)$ \\
DVV-D8 & $13.88(0.52)$ & $0.88(0.01)$ & $0.87(0.01)$ \\
DVV-D9 & $3.71(0.15)$ & $0.55(0.02)$ & $0.54(0.01)$ \\
DVV-D11 & $10.12(0.33)$ & $0.86(0.02)$ & $0.82(0.01)$ \\
DVV-T2 & $2.94(0.06)$ & $0.49(0.03)$ & $0.52(0.01)$ \\
DVV-ET1 & $3.35(0.13)$ & $0.56(0.02)$ & $0.62(0.01)$ \\
\hline
\end{tabular}

ferroni corrections for multiple tests. This indicated that the problem area samples were not composed of mixtures of differentiated populations causing a Wahlund effect.

The hierarchical F-statistics analysis did not detect significant population structuring at any level when all loci were considered together (Table 2). However, at the level of individual loci, a significant effect was observed between crops, within regions at locus DVV-T2 and another between samples, within crops, within regions at locus DVV-D5 (Table 2). To better understand the detailed patterns of genetic differentiation at these two loci, Fisher exact tests were conducted for each pair of samples (details not shown). At locus DVV-T2, these tests revealed that the observed population structuring was largely due to differentiation between the Monticello corn sample and most other samples, rather than a general differentiation between corn and soybean samples. Similarly, at locus DVV-D5, the observed structuring was driven by differentiation between the Flatville corn sample and most of the other samples, rather than a general differentiation between samples.

Finally, the Bayesian estimation of the number of populations in the total set of samples did not identify any population structure. All the posterior probability was on $K=1(P>0.999)$.

\section{Discussion}

Crop rotation has been compromised as a means of controlling western corn rootworm in part of the Corn Belt, apparently because of a loss of ovipositional fidelity to cornfields by the pest. This study tested the

Table 2. Hierarchical $\boldsymbol{F}$-statistics for individual microsatellite loci and all loci combined for western corn rootworm

\begin{tabular}{lccc}
\hline \hline Locus & $F_{\text {Region/Total }}$ & $F_{\text {Crop } / \text { Region }}$ & $F_{\text {Sample/Crop }}$ \\
\hline DVV-D2 & 0.0036 & -0.0003 & -0.0015 \\
DVV-D4 & 0.0029 & -0.0006 & -0.0041 \\
DVV-D5 & 0.0003 & -0.0015 & $0.0104^{* *}$ \\
DVV-D8 & -0.0008 & 0.0019 & 0.0023 \\
DVV-D9 & -0.0004 & -0.0023 & -0.0009 \\
DVV-D11 & 0.0019 & -0.0018 & 0.0002 \\
DVV-T2 & -0.0113 & $0.0131^{*}$ & -0.0045 \\
DVV-ET1 & 0.0008 & 0.0022 & -0.0103 \\
All & $2.5 \times 10^{-5}$ & 0.0012 & -0.0017 \\
\hline
\end{tabular}

Permutation test probabilities $\leq 0.05$ are indicated by $*$; those $\leq 0.01$ by **. hypothesis that resistance to crop rotation does not lead to genetic structuring. The data presented here indicate that this is indeed the case. We found no evidence for a departure from a single panmictic population either within the region of Illinois where crop rotation is ineffective or between this region and the surrounding area. The possibility of departures from panmixia was considered at two spatial scales: 1) between rotation-resistant and -susceptible beetles within the rotation resistance problem area and 2 ) between beetles within the problem area and those from the surrounding region. Within the problem area, systematic differentiation between samples from corn and soybean was not detected. This does not, of itself, prove that rotation-resistant and -susceptible beetles are undifferentiated. Potentially, differentiation could have been masked by a high incidence of rotation-resistant beetles in corn, to which they are known to return (Spencer et al. 1997, 1998, 1999b). However, a mixture of two genetically divergent populations in the same sample is expected to generate Hardy-Weinberg and linkage disequilibria. Very little evidence was found for such disequilibria in corn. Thus, within the rotation-resistance problem area there is a single, genetically homogenous western corn rootworm population. Finally, the lack of differentiation between samples inside and outside the problem area eliminates the possibility that a distinct resistant population has entirely replaced a susceptible population.

The observed homogeneity of microsatellite allele frequencies between the rotation-resistance problem area and the surrounding region is in keeping with the genetic homogeneity observed by Kim and Sappington (2005a) among samples of the western corn rootworm from widely separated locations throughout the Corn Belt. This lack of genetic structuring at a broad spatial scale may indicate that the western corn rootworm has a considerable capacity for long-range dispersal, possibly through migratory flights (Coats et al. 1986, Naranjo 1990). However, it should be noted that the time since the range expansion of this insect out of the central Great Plains to the Atlantic Coast, which began in the 1950s, may not have been long enough for structuring to accumulate by genetic drift. At a local scale, a bias toward mating between individuals from the same natal field could have the potential to restrict gene flow between rotation-resistant rootworms (which can emerge in rotated corn) 
and their rotation-susceptible counterparts (which are confined to continuous corn). Potentially, nonrandom mating also could occur because of pleiotropic effects of an adaptation to crop rotation. Nevertheless, the data presented here indicate that a combination of local dispersal by males seeking mates, females seeking oviposition sites, in addition to any long-range dispersal are sufficient to negate these effects, if they exist. However, as is the case for the general lack of geographical population structuring (Kim and Sappington 2005a), moderate reductions in gene flow might go undetected if there has not been sufficient time for significant genetic divergence to accumulate.

The finding that rotation-resistant and -susceptible western corn rootworms are indistinguishable at neutral microsatellite loci is encouraging for the sustainability of transgenic Bt cultivars. The primary method for managing the evolution of resistance to Bt toxins expressed by transgenic crops is the implementation of a refuge strategy. Refuge strategies are founded on the assumption that there is sufficient dispersal to ensure random mating between pests emerging from the refuge and those from the transgenic crop. Fortunately, resistance to crop rotation apparently does not seem to have resulted in local population structuring that would need to be accounted for in a refuge strategy.

Given the lack of general population structuring, genetic markers for rotation resistance probably will be found only at the gene or genes responsible, or at tightly linked loci. Such markers would be valuable for assessing whether rotation-resistant individuals are also present in introduced European populations of the western corn rootworm because crop rotation is required as part of the response to new outbreaks (European Commission Decision 2003/766/EC). This is especially important given the finding that new introductions to Europe from North America are ongoing and fairly frequent (Miller et al. 2005). Genetic markers for rotation resistance also would be of value in understanding evolution of the trait in the United States. Because of the manner in which rotation resistance has spread, it is likely that such markers will exhibit a clinal pattern of allele frequencies. Such markers are likely to be most frequent in and around Ford County, Illinois, where rotation resistance has been established for longest, and to decline in frequency toward the edge of the rotation-resistance problem area where there is likely to be greater mixing of rotation-resistant and -susceptible individuals. Analyzing clines of genes under selection has proven to be a powerful way of examining both contemporary patterns of dispersal and the strength of natural selection (Lenormand et al. 1999).

An important advance in understanding rotation resistance would be the mapping of the genes responsible. This would clarify both the number of genes involved and the strength of their contributions. However, this will require the identification of a measurable individual phenotype. In the absence of an identifiable phenotype, it may still be possible to identify variation in natural populations linked to rotation resistance genes by comparing divergence between rotation-resistant and -susceptible populations at many polymorphic markers. Research along these lines has been initiated in our laboratory. Markers linked to genes subject to diversifying selection are expected to show elevated differentiation compared with those influenced by genetic drift and migration alone (Wilding et al. 2001). This latter approach will require the comparison of samples that consist entirely of rotation-resistant or -susceptible individuals.

\section{Acknowledgments}

We thank Eli Levine for providing samples of western corn rootworm from Illinois. Tom Sappington and two anonymous reviewers gave valuable comments on earlier drafts of the manuscript. Funding of the work, including a postdoctoral grant supporting N.J.M., was provided by the Department Santé des Plantes et Environnement of the French Institut National de la Recherche Agronomique.

\section{References Cited}

Ball, H. J., and G. T. Weekman. 1962. Insecticide resistance in the adult western corn rootworm in Nebraska. J. Econ. Entomol. 55: 439-441.

Branson, T. F., P. L. Guss, and J. J. Jackson. 1977. Mating frequency of the western corn rootworm. Ann. Entomol. Soc. Am. 70: 506-508.

Cerda, H., and D. J. Wright. 2002. Could resistance to transgenic plants produce a new species of insect pest? Agric. Ecosyst. Environ. 91: 1-3.

Coats, S. A., J. J. Tollefson, and J. A. Mutchmor. 1986. Study of migratory flight in the western corn rootworm (Coleoptera: Chrysomelidae). Environ. Entomol. 15: $620-625$.

Devonshire, A. L., L. M. Field, S. P. Foster, G. D. Moores, M. S. Williamson, and R. L. Blackman. 1998. The evolution of insecticide resistance in the peach-potato aphid, Myzus persicae. Philos. Trans. R. Soc. Lond. Ser. B Biol. Sci. 353: 1677-1684.

Estoup, A., C. R. Largiadèr, E. Perrot, and D. Chourrout. 1996. Rapid one-tube extraction for reliable PCR detection of fish polymorphic markers and transgenes. Mol. Mar. Biol. Biotechnol. 5: 295-298.

Ferré, J., and J. Van Rie. 2002. Biochemistry and genetics of insect resistance to Bacillus thuringiensis. Annu. Rev. Entomol. 47: 501-533.

Goudet, J. 2005. Hierfstat, a package for R to compute and test hierarchical F-statistics. Mol. Ecol. Notes 5: 184.

Hartl, D. L., and A. G. Clark. 1997. Principles of population genetics. Sinauer, Sunderland, MA.

Hill, R. E. 1975. Mating, oviposition patterns, fecundity and longevity of the western corn rootworm. J. Econ. Entomol. 68: 311-315.

Kahler, A. L., A. E. Olness, G. R. Sutter, C. D. Dybing, and O. J. Devine. 1985. Root damage by western corn rootworm and nutrient content in maize. Agron. J. 77: 769774.

Kim, K. S., and T. W. Sappington. 2005a. Genetic structuring of western corn rootworm (Coleoptera: Chrysomelidae) populations in the U.S. based on microsatellite loci analysis. Environ. Entomol. 34: 494-503.

Kim, K. S., and T. W. Sappington. 2005b. Polymorphic microsatellite loci from the western corn rootworm (Insecta: Coleoptera: Chrysomelidae) and cross-amplifica- 
tion with other Diabrotica spp. Mol. Ecol. Notes 5: 115117.

Kiss, J., C. R. Edwards, H. K. Berger, P. Cate, M. Cean, S. Cheek, J. Derron, H. Festic, L. Furlan, J. Igrc-Bacic, et al. 2005. Monitoring of western corn rootworm ( $\mathrm{Di}$ abrotica virgifera virgifera LeConte) in Europe 1992 2003, pp. 29-39. In S. Vidal, U. Kuhlmann, and C. R. Edwards [eds.], Western corn rootworm: ecology and management. CABI Publishing, Wallingford, United Kingdom.

Lenormand, T., D. Bourguet, T. Guillemaud, and M. Raymond. 1999. Tracking the evolution of insecticide resistance in the mosquito Culex pipiens. Nature (Lond.) 400: 861-864.

Levine, E., and H. Oloumi-Sadeghi. 1996. Western corn rootworm (Coleoptera: Chrysomelidae) larval injury to corn grown for seed production following soybeans grown for seed production. J. Econ. Entomol. 89: 10101016.

Levine, E., J. L. Spencer, S. A. Isard, D. W. Onstad, and M. E. Gray. 2002. Adaptation of the western corn rootworm to crop rotation: evolution of a new strain in response to a management practice. Am. Entomol. 48: 94107.

Liu, Y.-B., B. E. Tabashnik, T. J. Dennehey, A. L. Patin, and A. C. Bartlett. 1999. Development time and resistance to Bt crops. Nature (Lond.) 400: 519.

Mabry, T. R., J. L. Spencer, E. Levine, and S. A. Isard. 2004. Western corn rootworm (Coleoptera: Chrysomelidae) behavior is affected by alternating diets of corn and soybean. Environ. Entomol. 33: 860-871.

Meinke, L. J., B. D. Siegfried, R. J. Wright, and L. D. Chandler. 1998. Adult susceptibility of Nebraska western corn rootworm (Coleoptera: Chrysomelidae) populations to selected insecticides. J. Econ. Entomol. 91: 594600 .

Metcalf, R. L. 1983. Implications and prognosis of resistance to insecticides, pp. 703-733. In G. P. Georghiou and T. Saito [eds.], Pest resistance to pesticides. Plenum, New York.

Miller, N. J., A. Estoup, S. Toepfer, D. Bourguet, L. Lapchin, S. Derridj, K. S. Kim, P. Reynaud, L. Furlan, and T. Guillemaud. 2005. Multiple transatlantic introductions of the western corn rootworm. Science (Wash., DC) 310: 992.

Naranjo, S. E. 1990. Comparative flight behavior of Diabrotica virgifera virgifera and Diabrotica barberi in the laboratory. Entomol. Exp. Appl. 55: 79-90.

O’Neal, M. E., C. D. DiFonzo, and D. A. Landis. 2002. Western corn rootworm (Coleoptera : Chrysomelidae) feeding on corn and soybean leaves affected by corn phenology. Environ. Entomol. 31: 285-292.

O’Neal, M. E., D. A. Landis, J. R. Miller, and C. D. Difonzo. 2004. Corn phenology influences Diabrotica virgifera virgifera emigration and visitation to soybean in laboratory assays. Environ. Entomol. 33: 35-44.

Onstad, D. W., M. G. Joselyn, S. A. Isard, E. Levine, J. L. Spencer, L. W. Bledsoe, C. R. Edwards, C. D. Fonzo, and H. Willson. 1999. Modeling the spread of western corn rootworm (Coleoptera: Chrysomelidae) populations adapting to soybean-corn rotation. Environ. Entomol. 28: 188-194

Onstad, D. W., J. L. Spencer, C. A. Guse, E. Levine, and S. A. Isard. 2001. Modeling evolution of behavioral resistance by an insect to crop rotation. Entomol. Exp. Appl. 100: 195-201.

Onstad, D. W., D. W. Crowder, C. A. Guse, J. L. Spencer, E. Levine, and M. E. Gray. 2003. Economics versus al- leles: balancing integrated pest management and insect resistance management for rotation-resistant western corn rootworm (Coleoptera: Chrysomelidae). J. Econ. Entomol. 96: 1872-1885.

Pierce, C.M.F. 2003. Case study of a variant of western corn rootworm Diabrotica virgifera virgifera LeConte in east central Illinois. Ph.D. dissertation, University of Illinois, Urbana-Champaign, IL.

Pritchard, J. K., M. Stephens, and P. Donnelly. 2000. Inference of population structure using multilocus genotype data. Genetics 155: 945-959.

Quiring, D. T., and P. R. Timmins. 1990. Influence of reproductive ecology on feasibility of mass trapping Diabrotica virgifera virgifera (Coleoptera: Chrysomelidae). J. Appl. Ecol. 27: 965-982.

Raymond, M., and F. Rousset. 1995. GENEPOP (version 1.2 ) - population genetics software for exact tests and ecumenicism. J. Hered. 86: 248-249.

Raymond, M., C. Chevillon, T. Guillemaud, T. Lenormand, and N. Pasteur. 1998. An overview of the evolution of overproduced esterases in the mosquito Culex pipiens. Philos. Trans. R. Soc. Lond. Ser. B Biol. Sci. 353: $1707-$ 1711.

Rondon, S. I., and M. E. Gray. 2004. Ovarian development and ovipositional preference of the western corn rootworm (Coleoptera: Chrysomelidae) variant in East Central Illinois. J. Econ. Entomol. 97: 390-396.

Spencer, J. L., E. Levine, and S. A. Isard. 1997. Corn rootworm injury to first-year corn: new research findings, pp. 73-81. In Proceedings, Illinois Agricultural Pesticides Conference, Cooperative Extension Service, University of Illinois, Urbana-Champaign, IL.

Spencer, J. L., S. A. Isard, and E. Levine. 1998. Western corn rootworms on the move: monitoring beetles in corn and soybeans, pp. 10-23. In Proceedings, Illinois Agricultural Pesticides Conference, Cooperative Extension Service, University of Illinois, Urbana-Champaign, IL.

Spencer, J. L., S. A. Isard, and E. Levine. 1999a. Free flight of western corn rootworm (Coleoptera: Chrysomelidae) to corn and soybean plants in a walk-in wind tunnel. J. Econ. Entomol. 92: 146-155.

Spencer, J. L., S. A. Isard, and E. Levine. 1999b. Western corn rootworm injury in first year corn: what's new?, pp. 73-81. In Proceedings, Illinois Crop Protection Technology Conference, Cooperative Extension Service, University of Illinois, Urbana-Champaign, IL.

Spencer, J. L., T. R. Mabry, and T. T. Vaughn. 2003. Use of transgenic plants to measure insect herbivore movement. J. Econ. Entomol. 96: 1738-1749.

Spencer, J. L., E. Levine, S. A. Isard, and T. R. Mabry. 2005. Movement, dispersal and behaviour of western corn rootworm adults in rotated maize and soybean fields, pp. 121-144. In S. Vidal, U. Kuhlmann, and C. R. Edwards [eds.], Western corn rootworm: ecology and management. CABI Publishing, Wallingford, United Kingdom.

[USEPA] U.S. Environmental Protection Agency. 2003. Bacillus thuringiensis Cry3Bbl protein and the genetic material necessary for its production (vector ZMIR13L) in event MON863 corn (006484) fact sheet. EPA, Washington, DC.

Wilding, C. S., R. K. Butlin, and J. Grahame. 2001. Differential gene exchange between parapatric morphs of Littorina saxatilis detected using AFLP markers. J. Evol. Biol. 14: 611-619.

Received 8 August 2005; accepted 13 January 2006. 